\title{
Announcement of Retraction
}

The editorial board announced this article has been retracted on January 14, 2021.

If you have any further question, please contact us at: ijhe@ sciedupress.com

Article Title: Scientific Bases the System of Future Fitness Coaches' Professional Training in Higher Educational Institutions

Author/s: Oksana Kornosenko, Pavlo Khomenko, Iryna Taranenko, Valeriy Zhamardiy, Olena Shkola, Hanna Tolchieva \& Volodymyr Saienko

Journal Title: International Journal of Higher Education

ISSN 1927-6044 E-ISSN 1927-6052

Volume and Number: Vol. 10, No. 2, 2021

Pages: 265-273

DOI: $10.5430 /$ ijhe.v10n2p265 